\title{
Qual a identidade das crianças nascidas de exploração sexual e abuso de forças de paz (capacetes azuis)? caso das crianças monusco ${ }^{12}$
}

Michel Mugaruka Kaboyi ${ }^{3}$

\section{RESUMO}

Não apenas os atos de violência sexual são intoleráveis, mas eles se parecem mais relevantes quando são praticados por membros de uma organização encarregada de desenvolver e encorajar o respeito aos direitos humanos. A República Democrática do Congo édependente da presença ininterrupta dos capacetes azuis possui diversas crianças conhecidas por MONUC ou MONUSCO, frutos das relações desiguais entre tropas de manutenção da paz, predadores sexuais, e meninas pobres, membros de comunidades locais que eles foram chamados para proteger. Os filhos desses relacionamentos transitórios , desde 1948, sob o palco das operações de paz, não conhecem essa vacilação permanente da contribuição parental para a formação do seu ser como homem e do advento de sua independência moral como sujeito portador de uma identidade.

Palavras-chave: Direitos Humanos. Monusco. Organização das Nações Unidas.

1 Missão de Estabilização da Organização das Nações Unidas na República Democrática do Congo. Data de recebimento: 16/02/2018. Data de aceite: 21/09/2018.

2 Tradução de Denise Boudoux de Mendonça, Procuradora do Ministério Público do Ceará. E-mail: deniseboudoux@mpce.mp.br e de Loraine Jacob Molina, Promotora do Ministério Público do Ceará. E-mail: loraine.molina@mpce.mp.br

3 Michel Mugaruka Kaboyi é formado em Direito Internacional Público pela Universidade Protestante do Congo e concluiu o Mestrado em Direito Internacional Público pela Universidade Católica de Louvain. Ele também foi treinado nas Universidades de Montreal e Moncton. Um veterano advogado e praticante, ele é consultor jurídico, magistrado de carreira, diretor do Centro de Pesquisa de Operações de Manutenção da Paz, COP na sigla, e um membro da Associação Internacional de Procuradores e Promotores Francófonos (AIPPF). E-mail: michel_kaboyil@yahoo.fr 


\title{
1 DOS ATOS DE EXPLORAÇÃO E DE ABUSO SEXUAIS
}

Não apenas os atos de violência sexual são intoleráveis, mas eles se parecem mais relevantes quando são praticados por membros de uma organização encarregada de desenvolver e encorajar "o respeito aos direitos humanos e às liberdades fundamentais por todos".

No ofício circular do Secretário Geral intitulado Disposições Especiais que visam prevenir a exploração e os abusos sexuais, o Secretário das Nações Unidas definiu exploração sexual e abuso sexual como sendo:

\begin{abstract}
A expressão "exploração sexual" significa o fato de abusar ou tentar abusar de um estado de vulnerabilidade, de hierarquia desigual ou de relações de confiança para fins sexuais, incluindo, mas não exclusivamente, para obter uma vantagem pecuniária social ou política. O "abuso sexual" é definido como qualquer agressão sexual cometida com força, coerção ou em uma relação desigual, e a ameaça de tal ataque também constitui abuso sexual. ${ }^{4}$
\end{abstract}

O termo violência sexual é, para ele, definido como um contato de natureza sexual imposto pela força, sob coação ou em benefício de um relacionamento desigual5.

Pode-se dizer que a utilização do termo "violência sexual" refere-se a comportamentos relacionados ao abuso sexual.

De acordo com a definição que lhe foi atribuída, resta evidente que se estabelece uma sinonímia entre "violência sexual" e "abuso sexual" na linguagem da ONU, senão simplesmente no direito internacional.

A título ilustrativo podemos ver uma similaridade na definição desses dois conceitos no texto

Elementos do Crime no Tribunal Penal Internacional", que, tratando de abuso sexual, indica ser um "ato de

4 SGNU, Dispositions spéciales visant à prévenir l'exploitation et les abus sexuels, doc off. Secrétariat des nations unies, circulaire du S.G, doc N.U ST/SGB/2003/13, 2005.

5 Idem. 
natureza sexual entre uma ou mais pessoas, obrigando a dita pessoa ou as pessoas a realizar tal ato pela força ou usando contra as referidas ou terceiras pessoas da ameaça de violência, coerção, detenção, pressões psicológicas, abuso de poder, ou em um ambiente coercitivo, ou ainda aproveitando a incapacidade de tais pessoas para dar seu livre consentimento. ${ }^{6}$

Segundo o Comitê Especial de operações de manutenção da paz sobre a estratégia global, que visa a eliminar a exploração e o abuso sexuais em operações de manutenção da paz, os atos de exploração e de abuso sexual

englobam uma gama de comportamentos que variam de violação das normas de conduta editadas pela Organização, como a solicitação de prostitutas adultas, que pode ser legal em alguns países, ou simplesmente não criminalizado, aos atos que seriam considerados, em qualquer país, como uma infração penal, tal qual estupro ou a pedofilia?

Podemos, portanto, afirmar que, à luz de tudo o que precede, atos que constituem falhas formais graves, são entendidos como tais, uma vez que seus autores cometem atos que valem como início de execução.

No entanto, ao longo dos anos, a lista de comportamentos qualificados nas disposições especiais que visam a prevenir a exploração e o abuso sexual foi expandida. Isto significa que a exploração e o abuso sexual, EAS abaixo, assume, portanto, uma infinidade de formas, incluindo estupro, relações sexuais com menores, agressões sexuais, tráfico de seres humanos, troca de dinheiro, de emprego, bens ou serviços por relações sexuais, solicitação de prostitutas, visualizações de pornografia, linguagem imprópria, pornografia in-

6 Art. $7.1 \mathrm{~g}-6$.

7 Rapport Zeid, note 4, p.9 ; cité par JULIE ROY, Les crimes sexuels et la responsabilité pénale du personnel du maintien de la paix des Nations Unis, Université du Québec à Montréal, Mémoire de Master, 2011, pp.10-11. 
fantil, distribuição de pornografia por email, exploração sexual de beneficiários e corrupção sexual de menores ${ }^{8}$.

Além disso, afirma-se nas declarações de Viena de 1993 e no seu programa de ação que as violências que "são praticadas em função do sexo e todas as formas de perseguição e exploração sexual são incompatíveis com a dignidade humana."

Assim, seria útil analisar o caso das crianças nascidas de abusos sexuais no teatro de manutenção da paz, bem como o seu acompanhamento, antes de realçar as dúvidas em torno de sua identidade.

\section{DO ACOMPANHAMENTO DAS CRIANÇAS NASCIDAS DOS CAPACETES AZUIS: O CASO DAS CRINÇAS MONUSCO}

O recrudescimento dos conflitos armados não internacionais, mesmo o das tensões internas, constituem ameaças contra a paz, e concorrem para a criação de operações de paz destinada a manter, restaurar, consolidar ou impor as condições para uma paz duradoura em países dilacerados por conflitos.

No entanto, estas operações são frequentemente acompanhadas por atos de exploração e abuso sexual, às vezes dando origem a gravidezes indesejadas, além da renovação da paz que trazem.

A República Democrática do Congo, a título ilustrativo, cuja paz na consolidação é, em grande parte, dependente da presença ininterrupta dos capacetes azuis (de forças de paz), por quase duas décadas, pulula com diversas crianças conhecidas por MONUC ou MONUSCO, frutos das relações desiguais entre tropas de manutenção da paz (capacetes azuis), e outros funcionários de missão civil, predadores sexuais, e meninas pobres, membros de comunidades locais que eles foram chamados para proteger.

O corolário desta ignomínia, fonte de impunidade universal, é

8 Circulaire, 2005. 
a hipoteca da educação e da identidade desta minoria de crianças vulneráveis, ignorantes das identidades de seus pais (geralmente); colocando, assim, a República Democrática do Congo no altar de países com baixa taxa de escolaridade, e fazendo dela um epicentro com alto grau de alistamento de crianças soldados, e isso por causa da ausência congênita de supervisão dos pais.

Evidentemente, o caso da República Democrática do Congo, com a presença de MONUSCO, é apenas uma amostra representativa do que se passa nas quinze outras operações de manutenção da paz. Os recentes procedimentos, sem continuidade, contra alguns oficiais congoleses (República Democrática do Congo e República do Congo), supostos perpetradores de exploração e abuso sexual na República Centroafricana, são os mais comentados.

Essa situação retraída, com ou sem razão, prevaleceu, sem dúvida, nos diferentes palcos de paz desde 1948, data da criação da primeira operação de manutenção de paz.

Apesar da imagem pintada dessa situação alarmante, encontramos uma política turva e indigesta na supervisão das referidas crianças pelos chefes das diversas missões da ONU, e suas instituições especializadas das Nações Unidas que trabalham neste campo, como a Organização das Nações Unidas pela educação, ciência e cultura (UNESCO), e o Fundos das Nações Unidas pela infância (UNICEF) em particular.

Para a UNESCO, note-se que sua criação ocorreu após a segunda guerra mundial, e comprometeu-se à luz das disposições e medidas necessárias tomadas pelos Pais fundadores das Nações Unidas a manter a paz e a segurança internacionais. Sob esse título, seu ato constituinte lhe atribuiu o objetivo de "contribuir na manutenção da paz, da segurança, no endurecimento através pela educação, ciência e cultura, a colaboração entre nações, a fim de garantir o respeito universal à justiça, a lei, aos direitos do homem e a liberdade para todos, sem distinção de raça, sexo, língua ou religião, que a carta das nações unidas reconhece a todas as pessoas." 
No que diz respeito à UNICEF, vale a pena destacar que ela se esforça para melhorar e promover as condições das crianças. Sua área de especialidade (a proteção e defesa dos direitos de cada criança) pode, nesse sentido, legitimamente justificar o papel principal na elaboração, concepção e promoção da Convenção Internacional sobre os Direitos das Crianças (CIDE) adotada na Cúpula de Nova York em 20 de novembro de 1939.

Além disso, tornou a proteção das crianças e a educação das meninas um objetivo prioritário.

No entanto, malgrado a clareza textual, uma prática ineficiente, consequência direta de uma inércia institucional generalizada, nos quadros de acompanhamento e escolarização das crianças, pelas duas instituições especializadas supracitadas, e pelas sessões de proteção infantil das diferentes missões, deixa-os intocados. Esta tragédia lança algumas dúvidas sobre a identidade dos filhos nascidos de atos de exploração e abuso sexual pelos 'capacetes azuis'.

\section{QUAISQUER DÚVIDAS SOBRE A IDENTIDADE DAS CRIAN- ÇAS NASCIDAS DE ATOS DE EXPLORAÇÃO E DE ABUSO SEXUAL POR CAPACETES AZUIS}

A questão da identidade é mais relevante que nunca. A identidade social, étnica, coletiva, cultural, sexual, pessoal ou individual, é tema que raramente parece ser tão presente e urgente, embora sempre os homens tenham se questionado sobre sua origem, sua pertença e sua especificidade 9 .

Em realidade, "a expressão mais íntima do indivíduo como pessoa é sua identidade"10.

9 la mode des identités, 1987 ; Le Page et Tabouret - Keller, 1985 ; Levi - Stress, Varo Gabrielle, Enfants et adolescents mixtes : une identité spécifique ? in enfance, tome 43, n³, 1990, p. 304. Voir aussi, Dressler - Holohan et al., 1986 1977, l'identité déchirée, 1983 : Magoudi, 1983, Noiriel, 1988, Oriel, 1984. 10 Janine Hohl et Michèle Normand, "Construction et stratégies identitaires des enfants et adolescents en contexte migratoire : le rôle des intervenants scolaires ", in revue française pédagogie, $\mathrm{n}^{\circ} 117$, octobre-novembre-décembre, 1996, p. 40. 
Pais e parentes estão envolvidos nas negociações sobre todos os aspectos de socialização de uma criança, com o objetivo de lhes imprimir o "selo cultural do seu lado da família" (Touzard, 1975). Toda criança é, assim, conscientemente ou não, um desafio entre linhagens e entre pais (de Singly, 1976). Compromisso e negociação estão constantemente em ação na educação recebida no seio da família, onde cada um dos pais tem sua ideia de valores, das maneiras, da "mentalidade" e do estilo que ele/ela deseja comunicar para a criança ou mesmo reproduzir ${ }^{11}$.

Os filhos de relacionamentos transitórios entre um pequeno grupo de soldados de paz, ou outros funcionários civis da ONU malévolos e algumas meninas vulneráveis da comunidade local, desde 1948, sob o palco das operações de paz, não conhecem essa vacilação permanente da contribuição parental para a formação do seu ser como homem e do "advento de sua independência moral"12 como sujeito portador de uma identidade.

Sem definir o que se entende por "identidade", o UNICEF determina seus elementos: cada criança tem o direito de ter um nome, uma nacionalidade. Tem direito a uma família, de ser cercado e amado. É um dos direitos da CIDE: desde o nascimento, a criança tem direito de conhecer seus pais e de ser criado por eles. ${ }^{13}$

Entretanto, para essas crianças (geralmente) ignorantes de sua identidade e dos próprios pais, surgem sérios problemas para o seu registro e estado civil.

E, ainda, ser registrado no nascimento é o primeiro dos direitos civis, porque ele atesta a existência e a identidade de uma criança. Sem o registro, a criança não pode ser protegida por não ter existência oficial (idem), e, portanto, sem identidade social, na medida em que a identidade de uma pessoa é a afirmação de sua existência dentro da sociedade. É, igualmente, o reconhecimento

11 VARO, G., op. cit, p. 306.

12 Janine Hohl et Michèle Normand, op.cit., p. 41.

13 Lire Unicef France, Le droit de l'enfant : le droit à l'identité, Fiche thématique, 2012. 
de sua individualidade e do que a diferencia dos seus próximos. ${ }^{14}$

Para acrescentar ao exposto, aos atos de exploração e de abuso sexual, é claro e sem equívoco que algumas dúvidas de confirmação de identidade ainda cercam seus filhos, os quais não se beneficiam de nenhuma ajuda militante para seu desenvolvimento social, canal importante de emergência enquanto a pessoa, portadora de uma identidade; e isso, inobstante a inovação trazida pela resolução 2272 da ONU de 2016 "qualificado de histórico" tendendo à criação de um fundo especial para o cuidado dessas crianças. Um sonho a realizar!

Em conclusão, o Secretário Geral das Nações Unidas não opinou que é possível incrementar rapidamente a situação oferecendo oportunidades aos jovens e dando-lhes esperança? Antes de continuar a aproveitar ao máximo o enorme potencial da população mundial atual, relativamente jovem, é necessário investir mais na educação, na formação e no trabalho decente e convencer os jovens a assumirem o controle do seu futuro?

(Ler "o Secretário Geral das Nações Unidas vê na África um continente cheio de esperança", in Echos de la MONUSCO, vol. IX, nº. 66,2017,p.07).

Ele juntou a fala ao ato? Por que ele não faz caso de que sejam seus filhos que representam até hoje uma minoria, cuja vulnerabilidade é causada por pessoas sob sua responsabilidade? Seus órgãos subsidiários, em especial?

Todo esse questionamento defende o estabelecimento de políticas reais de monitoramento e acompanhamento das espécies vulneráveis de crianças, as mães miseráveis. E sobre a identidade delas! 


\section{WHAT'S THE CHILDREN'S IDENTITY THAT WERE BORN IN SITUATION OF SEXUAL EXPLOITATION OF A PEACE FORCE? THE MONUSCO CHILDREN'S CASE}

\section{ABSTRACT}

Acts of sexual violence intolerable, but they seem more relevant when they are practiced by members of an organization charged with developing and encouraging respect for human rights. The Democratic Republic of Congo is dependent on the uninterrupted presence of blue helmets and has several children known to MONUC or MONUSCO, fruits of unequal relationships between peacekeepers, sexual predators and poor girls, members of local communities they were called to protect. The children of these transient relationships, since 1948, are not aware of this permanent vacillation of the parental contribution to the formation of their being as a man and of the advent of their moral independence as subject bearing an identity.

Keywords: Human Rights. Monusco. United Nations.

\section{REFERÊNCIAS BIBLIOGRÁFICAS}

Secretário Geral das Nações Unidas vê na África um continente cheio de esperança", in Echos de la MONUSCO, vol. IX, nº. 66,2017,p.07. SGNU, Dispositions spéciales visant à prévenir l'exploitation et les abus sexuels, doc off. Secrétariat des nations unies, circulaire du S.G, doc N.U ST/SGB/2003/13, 2005.

Rapport Zeid, note 4, p.9 ; cité par JULIE ROY, Les crimes sexuels et la responsabilité pénale du personnel du maintien de la paix des Nations Unis, Université du Québec à Montréal, Mémoire de Master, 2011, pp.10-11. la mode des identités, 1987 ; Le Page et Tabouret - Keller, 1985 ; Levi Stress, Varo Gabrielle, Enfants et adolescents mixtes : une identité spécifique ? in enfance, tome 43, n³, 1990, p. 304. Voir aussi, Dressler - Holohan et al., 
1986 1977, l'identité déchirée, 1983 : Magoudi, 1983, Noiriel, 1988, Oriel, 1984. Janine Hohl et Michèle Normand, "Construction et stratégies identitaires des enfants et adolescents en contexte migratoire : le rôle des intervenants scolaires ", in revue française pédagogie, n 117 , octobre - novembre - décembre, 1996, p. 40.

VARO, G., op. cit, p. 306.

Janine Hohl et Michèle Normand, op.cit., p. 41.

Lire Unicef France, Le droit de l'enfant : le droit à l'identité, Fiche thématique, 2012.

www.humanium.org consulté le 14 juin 2017 